\title{
EXPOSIÇÃO FOTOGRÁFICA E USO DO FACEBOOK PARA FINS EDUCACIONAIS
}

\author{
P. L. TORRES", D. C. BOARON, R. P. G. KOWALSKI \\ Pontifícia Universidade Católica do Paraná \\ patricia.lupion@pucpr.br
}

Submetido 20/06/2016 - Aceito 04/02/2017

DOI: $10.15628 /$ holos.2017.4737

\begin{abstract}
RESUMO
O presente artigo pretende expor o resultado de um processo de pesquisa qualiquantitativa do tipo estudo de caso, desenvolvido dentro de uma linha de pesquisa de um programa de pós-graduação stricto sensu em Educação de uma universidade particular de grande porte do Estado do Paraná, como parte das atividades de um dos grupos de pesquisa. Com base nas reflexões e discussões, acerca dos perfis de leitores sistematizados pela pesquisadora Lucia Santaella (2014), buscou-se uma maneira de explicar os conceitos e envolver o maior número de pessoas, estendendo a proposta para além dos participantes do grupo de pesquisa, com o objetivo de possibilitar a interação, a colaboração e a disseminação da temática. O objetivo desse estudo é analisar a experiência do desenvolvimento de uma exposição e do uso de uma rede social para fins
\end{abstract}

educacionais. A primeira fase centrou nas atividades realizadas no grupo de pesquisa com leituras, reflexões e discussões sobre o tema. A segunda fase focou na realização de uma exposição de fotografias e textos, denominada "Multiplicidade de Leitores", juntamente com a disseminação em uma página no Facebook, a qual possibilitou a compreensão e a interação por um extenso número de pessoas, ultrapassando os muros da instituição. Com base nos resultados obtidos foi possível perceber que o desenvolvimento dessa experiência foi positivo, por propiciar aos apreciadores o entendimento sobre o tema de modo interativo e dinâmico. Ademais, evidenciou-se que a rede social tem sido cada vez mais utilizada pelos professores como ambiente de aprendizagem, por possibilitar aos estudantes um espaço de troca, colaboração e liberdade de expressão.

PALAVRAS-CHAVE: Facebook, multiplicidade de leitores, rede social, Santaella.

\section{PHOTO EXHIBITION AND FACEBOOK USE FOR EDUCATIONAL PURPOSES}

\begin{abstract}
This article aims to expose the results of a qualiquantitative research process of a case study, developed within a research of a stricto sensu posgraduate program in Education at a large private university of Paraná State, as part of the activities of one of the research groups. Based on the reflections and discussions about the readers profiles systematized by the researcher Lucia Santaella (2014), it sought a way to explain concepts and involve more people, extending the proposal beyond the participants of the research group, in order to facilitate interaction, collaboration and dissemination of the theme. The aim of this study is to analyze the experience of the development of an exhibition and the use of a social network for educational purposes. The first phase of the study
\end{abstract}

focused on activities in the research group with readings, reflections and discussions on the topic. The second phase focused on the realization of an exhibition of photographs and texts, called "Multiplicity Readers", with the spread on a Facebook page, which enabled the understanding and interaction by a large number of people, surpassing the walls of institution. Based on the results we can see that the development of this experience was positive, for providing the appreciators understanding on the topic of interactive and dynamic way. Moreover, it was shown that the social network has been increasingly used by teachers as a learning environment, enabling students a space for exchange, collaboration and freedom of expression.

KEYWORDS: Facebook, multiple readers, social network, Santaella. 


\section{INTRODUÇÃO}

Com a explosão da internet e a democratização ao acesso, profundas mudanças ocorrem na sociedade e, em especial, na educação. A interatividade, o compartilhamento, a colaboração e a produção de conteúdos são palavras-chave que permeiam esse novo cenário digital. Com a massificação de recursos tecnológicos somada a facilidade de utilizar, produzir e publicar recursos na web, os usuários, que antes apenas navegavam pelos conteúdos estáticos, tornam-se atores, os quais podem interagir, trocar e contribuir na criação de novas informações. Nesse novo contexto de abertura e produção de conhecimento, as instituições de educação superior devem repensar seu papel na sociedade, pois não são mais os únicos espaços para o acesso à informação.

Concordando com Moraes (2008, p. 16) quando afirma que "um mundo globalizado é um mundo em rede", compreende-se que por meio das tecnologias de informação e comunicação (TICS), milhões de pessoas conectam-se instantaneamente via dispositivos digitais, formando uma grande rede de informações, amizades, interesses e aprendizagem. Ao longo dos anos, as TICs têm mudado a maneira de pensar e agir dos usuários e, em especial, o perfil dos estudantes que chegam as instituições educativas. Os chamados "nativos digitais" (Prensky, 2001), nasceram e cresceram numa sociedade globalizada, na qual, a distância de um clique, utilizam a internet e as redes sociais em todos os momentos de suas vidas.

Com o advento da web 2.0, as redes sociais surgiram na internet e atraíram inscritos espalhados pelo mundo inteiro. Hoje, o Facebook, o mais utilizado (Sumares, 2016), faz parte do cotidiano de inúmeras pessoas, empresas e instituições educativas. Devido suas potencialidades, favorece o compartilhamento instantâneo e interativo de conteúdos, notícias e recursos, e permite a comunicação e troca de ideias entre pessoas geograficamente distantes. Por esses e outros fatores, grande parte dos estudantes já utilizam essa rede social para buscar conteúdos educacionais, informações e fazer contatos.

Sendo assim, concordando com Amante (2015, p. 41) quando afirma que "as redes sociais estão presentes no nosso dia a dia. Mas, mais do que estarem presentes elas marcam efetivamente a sociedade atual", considerar a inserção de práticas de ensino envolvendo o uso desses sites na educação superior, condizentes com o perfil e a realidade dos estudantes e com a complexidade do mundo atual, torna-se imprescindível.

\section{REDES SOCIAIS}

No início deste século, a educação tem-se desenvolvido em uma sociedade na qual o compartilhamento, a colaboração e a produção de conteúdos são palavras de ordem. As redes sociais, protagonistas desse cenário, permitem a liberdade de expressão, a troca, o diálogo e a aprendizagem colaborativa em um ambiente aberto, gratuito e sem hierarquias.

De acordo com Santaella (2014, p. 33), com a popularização do acesso à internet banda larga, que permitiu o armazenamento de informações na rede (nuvem), facilitou o comércio eletrônico e difundiu as redes sociais, a web tornou-se um espaço democratizado, no qual os conteúdos gerados pelo usuário podem ser compartilhados e mantidos pela conectividade social. 
Segundo a autora, "a internet tornou-se assim um hiperespaço plural, no qual são produzidas, publicadas, distribuídas e consumidas mensagens multimídia” (Santaella, 2014, p. 33).

Nesse sentido, Macedo \& Ribes (2014, p. 150) afirmam que a transição da web 1.0 para a web 2.0 gerou uma mudança radical na estrutura comunicacional: "[...] o modelo de produção 'um-para-todos' é substituído pelo formato 'todos-todos', o que significa, na prática, a chamada liberação do polo de emissão que rompe com formas clássicas de produção de conteúdos e mensagens" (Macedo \& Ribes, 2014, p. 150). Nesse novo cenário, os usuários, que antes apenas consumiam os conteúdos estáticos, podem contribuir na criação de informações, participando de um processo de construção coletiva do conhecimento. Nesse sentido, Okada (2011, p. 7) afirma que:

\begin{abstract}
A facilidade de acessar, reconstruir e trocar na Web 2.0 é uma das grandes vantagens desta nova geração da internet na qual qualquer usuário - seja docente, pesquisador, ou estudante - pode participar ativamente como coaprendiz crítico, coautor criativo e coprodutor colaborativo.
\end{abstract}

Além disso, com a explosão das redes sociais, "[...] as meninas dos olhos da Web 2.0" (Santaella, 2014, p. 33), pessoas geograficamente distantes podem conectar-se e interagir em tempo real, criando redes de amizades, estudo e trabalho. Por se tratarem de espaços abertos, não há barreiras de acesso; qualquer pessoa, desde que tenha acesso à internet, pode participar.

Assim, Macedo \& Ribes (2014, p. 153) definem que: "as redes sociais online são, portanto, uma grande arena de encontro, de diálogo e de produção de sentidos". Complementando essa definição, Santaella (2014, p. 33) afirma que "são redes de cooperação recíproca nas quais se fazem coisas e se resolvem problemas juntos". Para tanto, vale ressaltar que "[...] é preciso levar em conta que as redes são constituídas pelos participantes que delas se utilizam, pois, sem eles, as redes não poderiam existir" (Santaella, 2014, p. 33).

Posto isso, Moreira \& Januário (2014, p. 74) acreditam que "[...] sendo as redes sociais espaços coletivos e colaborativos de comunicação e de troca de informação, podem facilitar a criação e desenvolvimento de comunidades de prática ou de aprendizagem desde que exista uma intencionalidade educativa explícita". Além disso, por serem espaços comumente e diariamente utilizados pelos jovens, apresentam-se como possibilidade de resposta para a criação de práticas educacionais condizentes com o perfil desses, pois, conforme Palloff \& Pratt (2015, p. 22): “os estudantes exigem cada vez mais a inclusão de tecnologia nos cursos, e os docentes precisam responder a essa exigência".

Portanto, dada as potencialidades das redes sociais, torna-se essencial conhecer e investigar tais espaços, para explorar as possibilidades e recursos, os quais permitirão a construção de práticas de ensino abertas e colaborativas.

\title{
3 FACEBOOK
}

O Facebook, rede social com mais adeptos no Brasil, além de ser um espaço gratuito de comunicação instantânea e socialização, oferece ferramentas e recursos que podem ser utilizadas para fins educacionais. Devido a grande popularidade entre os jovens, revela-se como uma opção para o professor, que pode aproveitar as funcionalidades para o desenvolvimento de práticas de ensino condizentes com o perfil e expectativas dos estudantes. 
Criado em 2004 por Mark Zuckerberg, estava disponível apenas para os estudantes das universidades americanas. Em 2006, a rede foi aberta para todos os internautas, expandindo-se e atraindo jovens pelo mundo inteiro (Moreira \& Januário, 2014). Em virtude dos recursos disponíveis, tais como: publicações, mensagens privadas, grupos abertos e fechados, calendário, criação de eventos, envio de vídeos e fotos e os botões compartilhar e curtir, que recentemente ganhou reações para expressar sentimentos, tornou-se um espaço de interação e comunicação amplamente acessado.

Em novembro de 2015, Zuckerberg anunciou em sua página pessoal ${ }^{1}$ que a rede contava com mais de 1,55 bilhão de pessoas por mês, incluindo mais de 1 bilhão de usuários ativos acessando a rede diariamente. Segundo o criador, outros serviços da empresa, como o WhatsApp, o Messenger e o Instagram, contavam com 900 milhões, 700 milhões e 400 milhões de usuários ativos por mês, respectivamente. De acordo com Cruz (2016), em janeiro de 2016, na Campus Party Brasil ${ }^{2}$, o diretor de parcerias estratégicas da rede social, Ime Archibong, anunciou alguns dados referentes ao Brasil, tais como: a rede conta com 99 milhões de usuários ativos por mês; 89 milhões de usuários ativos via dispositivos móveis; e 8 em cada 10 brasileiros conectados estão no Facebook.

Esses números evidenciam que atualmente o Facebook é a rede social mais utilizada, fazendo parte do cotidiano de muitas pessoas. Nesse sentido, para Moreira \& Januário (2014, p. 78):

[...] o professor pode aproveitar as muitas horas que os seus estudantes passam conectados, para utilizá-lo como um espaço de partilha de conteúdos multimédia, de vídeos, de músicas, de fragmentos de filmes ou de peças de teatro, relacionados com os temas lecionados. Para, além disso, pode, também, aproveitar esse tempo para promover discussões e debates sobre os assuntos tratados.

Um dos pontos fortes do uso do Facebook, segundo Santaella (2014, p. 38), é que os usuários não se limitam a apenas consumir os conteúdos, mas sim, participam da produção desses. Além disso, por ser um espaço aberto, muito popular e fácil de utilizar, essa rede social possibilita que estudantes, professores, pesquisadores e especialistas conectem-se, trocando e construindo conhecimento de forma colaborativa e significativa, ultrapassando os muros da universidade.

Porém, Moreira \& Januário (2014, p. 75) alertam para o fato de que, por não se tratar de um ambiente criado com objetivos educacionais, o professor precisa dominar os recursos e as funcionalidades para que os utilize de forma adequada, evitando que a rede se torne somente um repositório de informações. Assim, o docente precisa "[...] otimizar a rede, promovendo uma forma de aprender com objetivos bem delineados, metodologias e avaliações bem claras e coerentes com os princípios de uma aprendizagem que se deseja colaborativa e construtivista" (Moreira \& Januário, 2014, p. 75).

\footnotetext{
${ }^{1}$ Disponível em:

<https://www.facebook.com/photo.php?fbid=10102457977071041\&set=a.529237706231.2034669.4\&type=3\&thea ter> Acesso em: 12 jun. 2016.

2 "Campus Party é a maior experiência tecnológica do mundo nas áreas de: Inovação, Criatividade, Ciência, Empreendedorismo e Entretenimento Digital" ("Sobre nós", s.d.).
} 
Sendo assim, evidencia-se a necessidade de investigar o desenvolvimento de propostas educacionais utilizando as potencialidades do Facebook, que possibilitem que o processo de ensino e aprendizagem seja mais significativo, tanto para os estudantes quanto para o professor.

\title{
4 MULTIPLICIDADE DE LEITORES
}

Devido as mudanças ocorridas na sociedade nos últimos anos, o acesso a informação se modifica e o conceito de leitura também.

Além das páginas dos livros, as informações estão espalhadas por todos os lados; nas ruas das grandes metrópoles, na televisão, nas redes sociais e na internet. Nesse sentido, de acordo com Santaella (2014, p. 29):

\begin{abstract}
Consequentemente, não há por que manter uma visão purista da leitura restrita à decifração de letras. Do mesmo modo que, desde o livro ilustrado e as enciclopédias, o código escrito foi historicamente se mesclando aos desenhos, esquemas, diagramas e fotos, o ato de ler foi igualmente expandindo seu escopo para outros tipos de linguagens. Nada mais natural, portanto, que o conceito de leitura acompanhe essa expansão
\end{abstract}

Sendo assim, a pesquisadora Lucia Santaella (2014) sistematizou a multiplicidade de leitores em quatro grandes tipos: contemplativo, movente, imersivo e ubíquo.

O primeiro tipo refere-se a era do livro impresso e da imagem expositiva, sua principal característica é a leitura individual, silenciosa, em um espaço retirado e privado. O leitor contemplativo tem uma "[...] leitura concentrada, que pode ser suspensa imaginativamente para a meditação e que privilegia processos de pensamento caracterizados pela abstração e a conceitualização" (Santaella, 2014, p. 30).

O leitor movente, que surgiu no auge da televisão, nos grandes espaços urbanos, está acostumado com a mistura de linguagem e sinais das metrópoles. É o "[...] leitor de luzes que se acendem e se apagam [...]; leitor apressado de linguagens efêmeras, híbridas, misturadas" (Santaella, 2014, p. 30).

Já o perfil imersivo, acostumado com tecnologia, computadores e que surgiu nos espaços das TICs, é o leitor que "[...] navega em telas e programas de leituras, num universo de signos evanescentes e eternamente disponíveis" (Santaella, 2014, p. 31).

Por fim, o leitor ubíquo, aquele que está presente fisicamente e no ciberespaço ao mesmo tempo, "[...] pode penetrar no ciberespaço informacional, assim como pode conversar silenciosamente com alguém ou com um grupo de pessoas a vinte centímetros ou a continentes de distância" (Santaella, p. 35, 2014).

A autora ressalta que "[...] um tipo de leitor não leva o outro ao desaparecimento. Cada um deles aciona habilidades cognitivas específicas de modo que um não pode substituir o outro" (Santaella, p. 36, 2014), isto é, os quatro tipos coexistem e se completam.

Devido a essas mudanças de perfis, segundo a autora, o maior desafio para a educação de hoje, "[...] é o da criação de estratégias de integração dos quatro tipos de leitores, contemplativo, 
movente, imersivo e ubíquo, ou seja, estratégias de complementação e não de substituição de um leitor pelo outro" (Santaella, p. 36, 2014).

\section{PROPOSTA EDUCACIONAL UTILIZANDO O FACEBOOK}

A investigação foi realizada dentro de uma linha de pesquisa de um programa de pósgraduação stricto sensu em Educação (PPGE) de uma universidade particular de grande porte do Estado do Paraná, como parte das atividades de um dos grupos de pesquisa.

Essa experiência foi desenvolvida em outubro de 2014 por integrantes do grupo de pesquisa, orientados pela professora líder do grupo. Com base nas reflexões e discussões, realizadas quinzenalmente, acerca dos perfis de leitores sistematizados pela pesquisadora Lucia Santaella (2014) - contemplativo, movente, imersivo e ubíquo -, buscou-se uma maneira de explicitar os conceitos e envolver o maior número de pessoas - estendendo a proposta para além dos participantes pertencentes ao grupo de pesquisa -, de modo que possibilitasse a interação e a disseminação da temática.

Sendo assim, com base na pesquisa e discussão do assunto, foi realizada uma exposição denominada "Multiplicidade de Leitores", na qual foi possível visualizar os perfis de leitores sistematizados por Santaella por meio de fotografias e textos. Com o objetivo de envolver várias pessoas oriundas das mais distintas áreas do conhecimento, essa exposição foi organizada de forma itinerante em dois espaços de ampla circulação na universidade: primeiramente na escola de Arquitetura e Design, e em seguida na escola de Educação e Humanidades.

A exposição (Figura 1) foi composta por dezesseis fotografias; dezesseis citações; quatro imagens com a descrição de cada perfil de leitor; além de um cartaz de abertura, o qual apresentava a temática da exposição e o direcionamento para a página on-line.

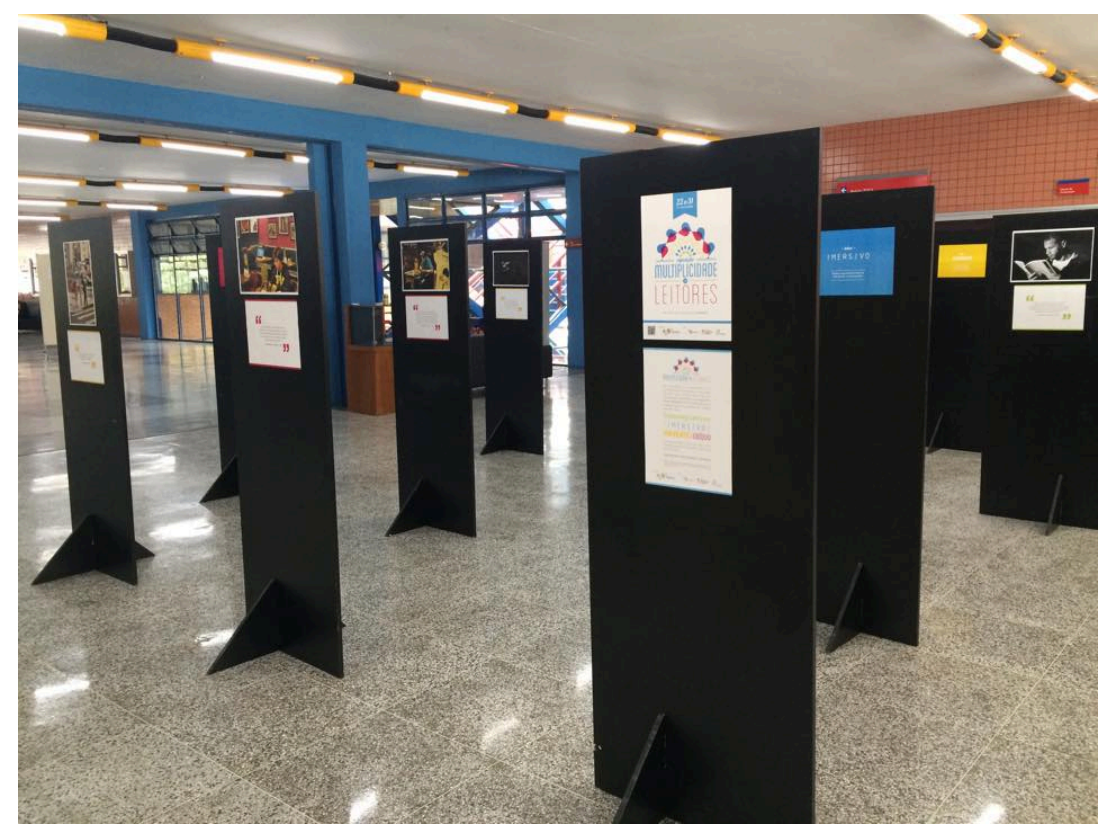

Figura 1: Exposição "Multiplicidade de Leitores". 
Com o objetivo de expandir e disseminar a temática em um canal de comunicação on-line, foi criada uma página na rede social Facebook (Figura 2), para que os visitantes pudessem publicar fotos e/ou vídeos sinalizando qual dos quatro tipos de leitores se identificavam. Para facilitar o acesso e a rápida publicação na internet, além da divulgação do endereço eletrônico no cartaz de abertura, foram distribuídos cartões com $Q$ Rcodes ${ }^{3}$ que direcionavam à página. Dessa forma, além de possibilitar a visualização e a compreensão da temática por aqueles que visitavam a exposição na universidade, essa experiência oportunizou a disseminação on-line das informações, atingindo um extenso número de pessoas, ultrapassando os muros da instituição.

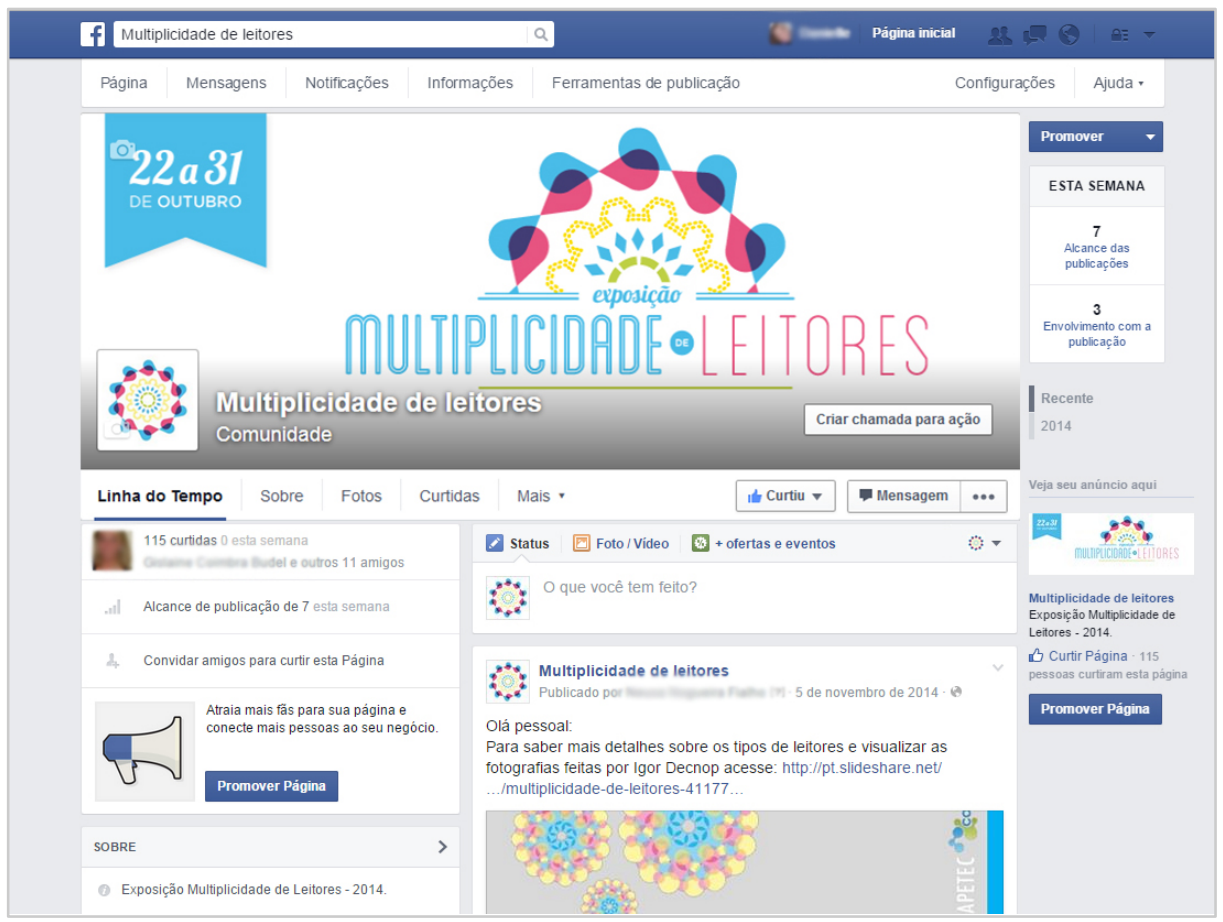

Figura 2: Página do Facebook

A exposição foi planejada para que o apreciador pudesse identificar-se com algum dos quatro tipos de leitores expostos, de modo a compreender sua própria forma de leitura e ampliar a percepção sobre a multiplicidade que emergiu das redes de comunicação planetárias. Por meio de registro audiovisual, alguns participantes foram entrevistados a respeito dos hábitos de leitura, temas de interesse e o perfil identificado. Posteriormente essas entrevistas em vídeo foram publicadas na página do Facebook (Figura 3).

\footnotetext{
“"É um código de barras em 2D que pode ser escaneado pela maioria dos aparelhos celulares que têm câmera fotográfica. Esse código, após a decodificação, passa a ser um trecho de texto, um link e/ou um link que irá redirecionar o acesso ao conteúdo publicado em algum site" (Prass, 2011).
} 


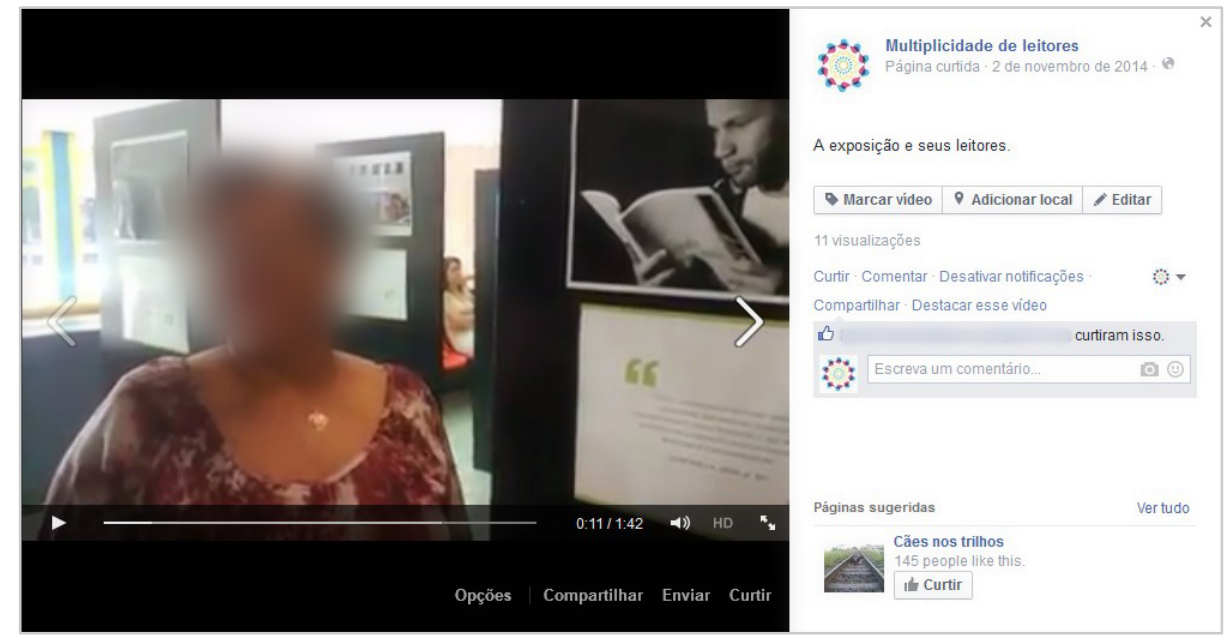

Figura 3: Entrevista com os apreciadores publicada no Facebook.

Devido à grande aceitação e repercussão dentro da universidade, a exposição, que foi incialmente programada para ocorrer de 22 a 31 de outubro, foi prorrogada até a primeira semana de novembro de 2014, possibilitando que mais pessoas pudessem apreciar e interagir na rede social. Durante os dias de exibição, alguns professores - das mais distintas áreas do conhecimento, tais como: pedagogia, design, educação física etc. - levaram suas turmas de graduação até o espaço de exposição, possibilitando, então, que os estudantes fossem apresentados à temática (estudantes, esses, que devido a área de formação, talvez não tivessem essa oportunidade).

\section{PROCEDIMENTO METODOLÓGICO DA PESQUISA}

Essa pesquisa foi conduzida pela abordagem qualiquantitativa do tipo estudo de caso. Utilizando-se da afirmação de Creswell \& Plano Clark (2007), Creswell (2010, p. 27) comenta que a pesquisa que combina métodos mistos (qualitativo e quantitativo), "[...] é mais do que uma simples coleta e análise dos dois tipos de dados", ela envolve "[...] o uso das duas abordagens em conjunto, de modo que a força geral de um estudo seja maior do que a da pesquisa qualitativa ou quantitativa isolada". Já o estudo de caso, segundo Yin (2005, p. 32), "investiga um fenômeno contemporâneo dentro de seu contexto da vida real, especialmente quando os limites entre o fenômeno e o contexto não estão claramente definidos". Complementando essa definição, Gil $(2009$, p. 14) afirma que o estudo de caso é útil para proporcionar uma visão mais clara a respeito dos fenômenos pouco explorados, além de abranger "[...]um espectro de possibilidades muito mais amplo que o da maioria dos delineamentos de pesquisa".

Os dados para análise foram obtidos por meio de dois instrumentos. Primeiramente, por meio da página on-line, foi possível contabilizar os dados estatísticos, tais como: gênero, país, cidade de todos os sujeitos envolvidos e o alcance de cada publicação (Figura 4). 


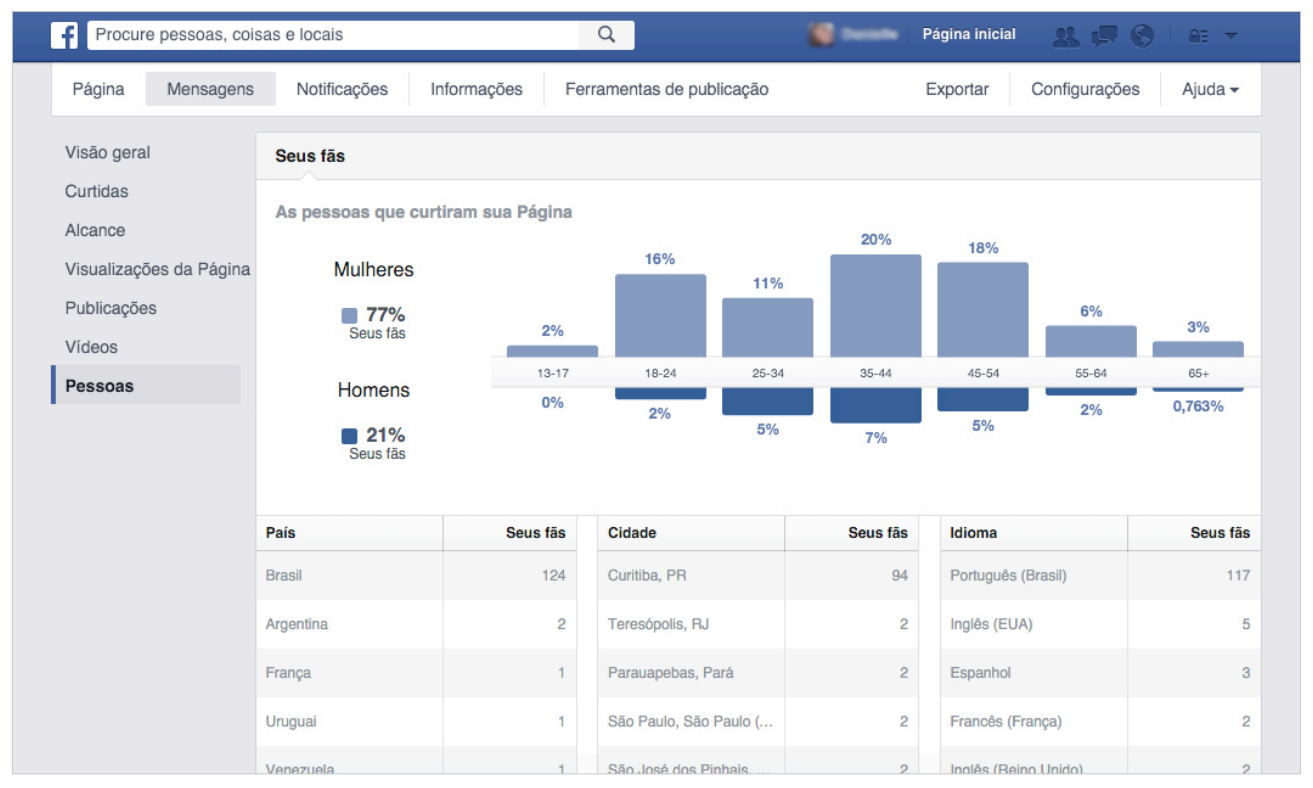

Figura 4: Dados estatísticos gerados na página do Facebook.

Em seguida, após o término da experiência, as pesquisadoras elaboraram um segundo instrumento de pesquisa com o objetivo de aprofundar o estudo. Para tal, optou-se por desenvolver um questionário composto por questões abertas, por possibilitar que o participante pudesse expressar livremente sua opinião a respeito do assunto, sem limitar-se a escolha entre as opções hipoteticamente previstas pelas pesquisadoras.

Para a elaboração do instrumento foi utilizado o serviço on-line do Google Drive ${ }^{4}$, o qual, além de possibilitar maior flexibilização no envio, ao término da pesquisa, automaticamente organiza os dados em uma planilha, ação, essa, que agiliza o processo de estruturação e posterior análise pelo pesquisador.

O universo da pesquisa foi composto pelos integrantes de três grupos de pesquisa da instituição, os quais tiveram ligação direta com a exposição. Desses, sete pessoas responderam o questionário de forma voluntária, constituindo, então, a amostragem desse segundo momento de investigação.

\section{RESULTADOS E DISCUSSÃO}

Com base na análise dos dados gerados pelo Facebook, constatou-se que a maior parte das pessoas que curtiram a página são mulheres (77\%) que se encontram na faixa etária de 35-44 anos, conforme observa-se na Figura 5.

\footnotetext{
${ }^{4}$ Disponível em: <www.google.com.br/drive>. Acesso em: 12 jun. 2016.
} 


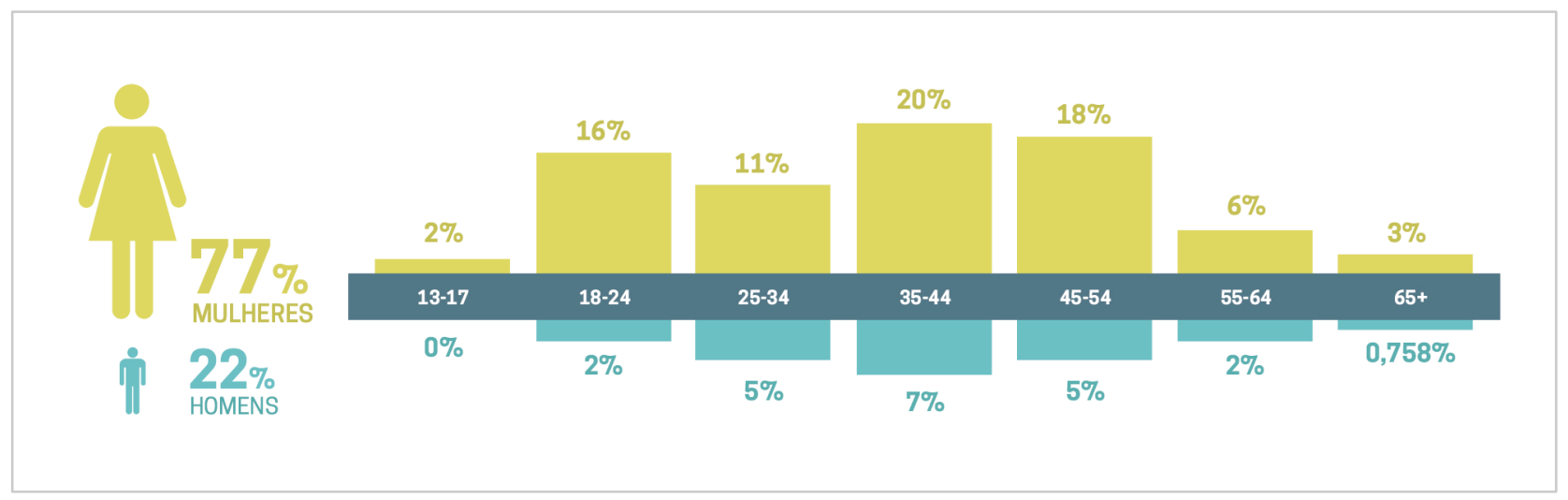

Figura 5: Perfil das pessoas que curtiram a página.

Em relação ao país de origem dos participantes, de acordo com o relatório do Facebook, 125 são do Brasil (Paraná, São Paulo, Rio de Janeiro, Amapá, Rio Grande do Sul, Pernambuco, Paraíba, Minas Gerais, Santa Catarina, entre outros); 2 da Argentina; e 5 distribuídos entre a França, o Uruguai, a Venezuela e a Espanha (Figura 6).

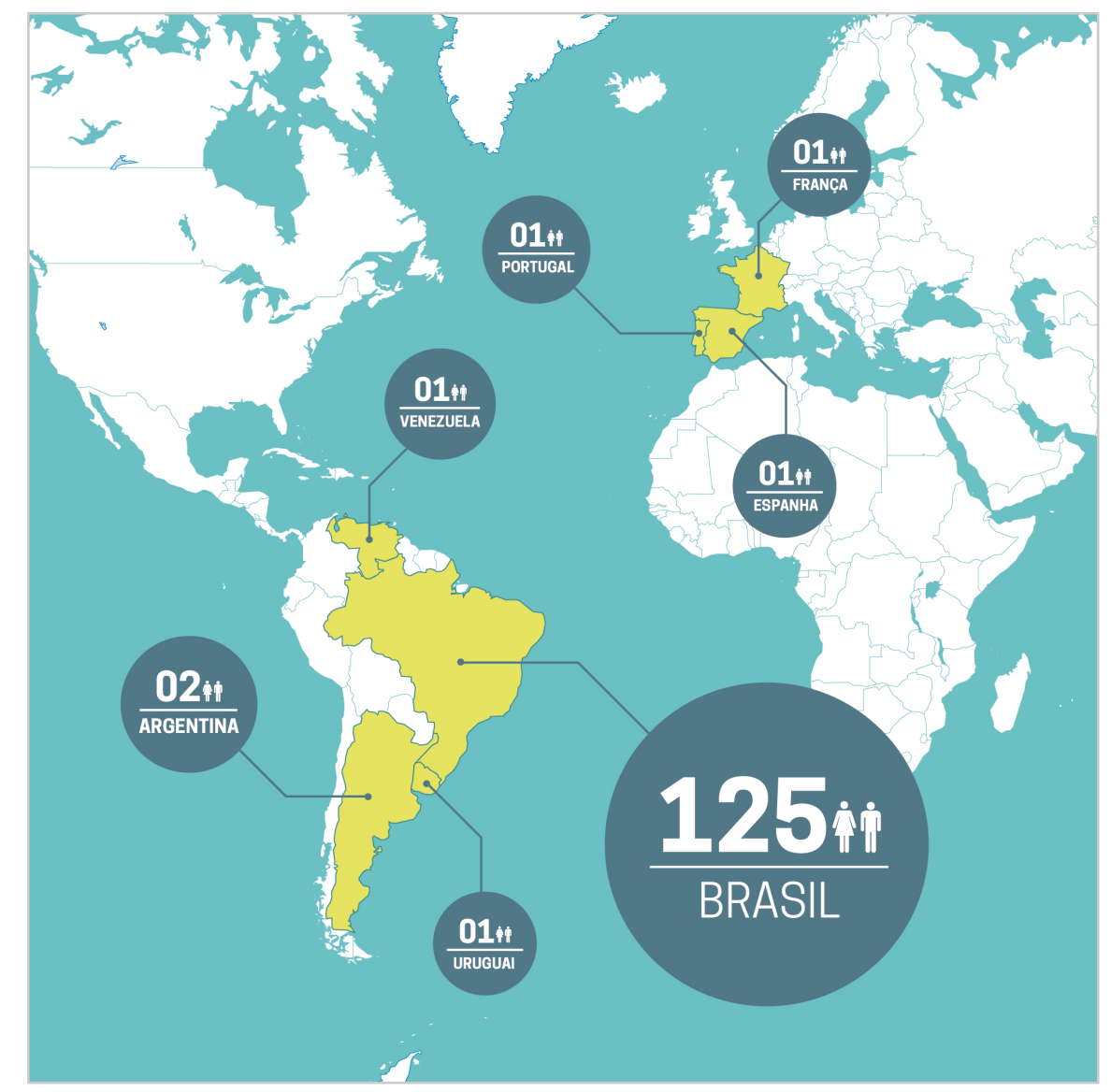

Figura 6: Países de origem das pessoas que curtiram a página.

Com relação ao alcance das publicações, na primeira semana de divulgação, a página teve um alcance total de 1.398 pessoas, como pode ser observado na Figura 7. 


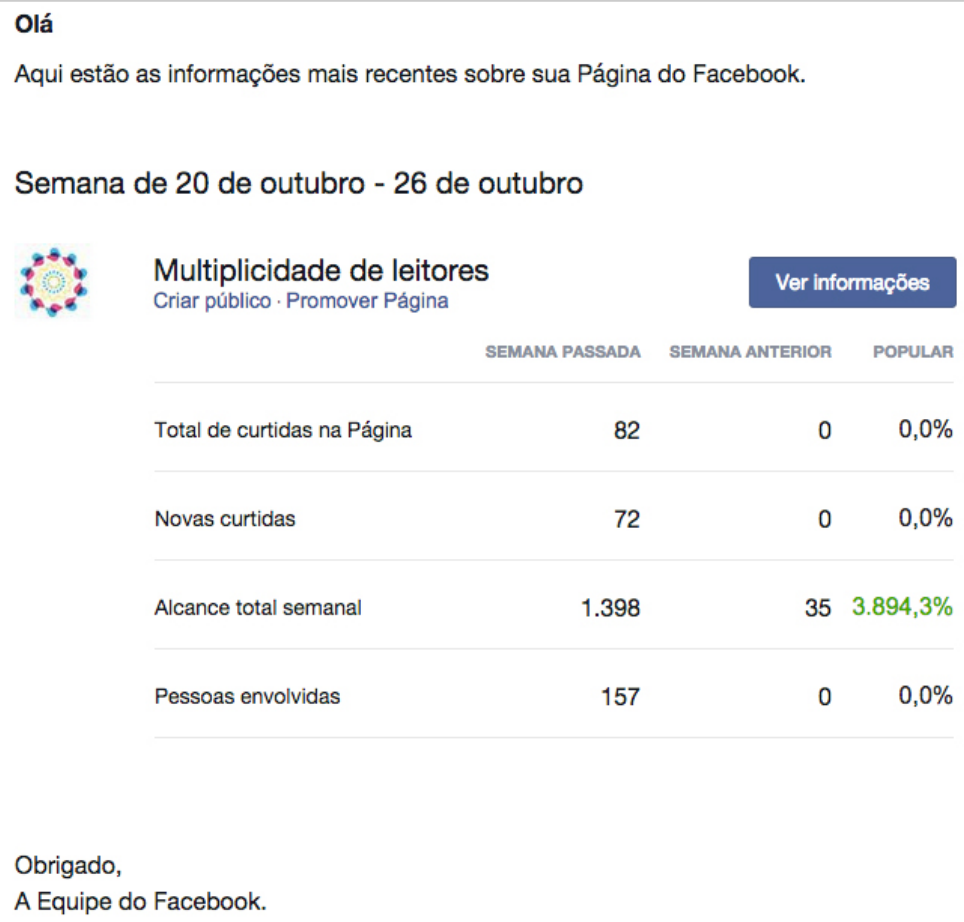

Figura 7: Notificação enviada pelo Facebook com as informações recentes sobre a página.

Esses dados (Figura 6 e Figura 7) demonstram que um dos objetivos desta experiência oportunizar a disseminação on-line das informações, atingindo um extenso número de pessoas, ultrapassando os muros da instituição -, foi atingido, pois, a partir das curtidas e compartilhamentos das postagens, distintas pessoas foram alcançadas em um curto espaço de tempo.

Com base na análise dos dados qualitativos obtidos por meio do segundo instrumento de pesquisa, constatou-se que todos os envolvidos afirmaram utilizar o Facebook diariamente, além de realizarem (ou já realizaram) atividades neste site de rede social para fins educacionais. Das contribuições, pode-se destacar o depoimento a seguir:

\begin{abstract}
Sim, várias vezes. Realizei atividades no Facebook com meus alunos da especialização. Com atividades de aprendizagem colaborativa, criava um grupo fechado nesta rede social da minha disciplina e desenvolvia atividades de compreensão e entendimento da matéria. Utilizava diversas ferramentas do Facebook como vídeos, imagens, aplicativos para facilitar a aprendizagem e interagir com os alunos (P04).
\end{abstract}

Além disso, os participantes destacaram que ao utilizar o Facebook em suas disciplinas, foi possível observar uma resposta positiva pelos estudantes, como afirma P01:

Sim, em minhas próprias aulas, ministradas no ensino superior. Utilizo frequentemente esta rede social para fins educacionais e a resposta dos alunos é sempre positiva (P01). 
Ao serem questionados sobre o uso desse site de rede social aliado a exposição física, os respondentes destacaram que foi positivo por consolidar a temática e, consequentemente, contribuir para esse entendimento, além disso, o alcance a um vasto número de pessoas foi ressaltado. Das contribuições, pode-se destacar as seguintes:

\begin{abstract}
Experiência enriquecedora por oportunizar conhecer mais sobre a referida autora, além de proporcionar uma forma diferenciada de interação com o tema e poder compartilhar em rede social, inclusive com visualizações por pessoas que não faziam parte do grupo. Isso amplia a possibilidade de acesso às informações por um número maior de pessoas (P01).

Sim! A exposição física construiu os conceitos teóricos, mas a prática só conseguiu fazer sentido no ambiente virtual com as contribuições (P02).

Sim, permite um melhor entendimento, envolvimento e interação no desenvolvimento da atividade proposta (P04).
\end{abstract}

Unanimemente, entre os respondentes, o Facebook é visto como uma ferramenta que pode e deve ser utilizada para fins educacionais por contribuir para o processo de ensino e aprendizagem. No entanto, ressaltam que o uso está diretamente relacionado com a proposta metodológica do professor, pois, por se tratar de um ambiente que não foi criado com objetivos educacionais, é imprescindível que o docente saiba como utilizá-lo de modo que não se perca a proposta pedagógica. Nessa perspectiva, "é necessário que o professor seja capaz de selecionar a informação, de problematizar em cima das informações para que possa ensinar e aprender" (FERREIRA; CORRÊA; TORRES, 2012, p. 10).

Devido às mudanças da sociedade advindas da globalização, surge a necessidade de se buscar novos meios e maneiras de superar os métodos tradicionais de ensino, pois, "os estudantes exigem cada vez mais a inclusão de tecnologia nos cursos, e os docentes precisam responder a essa exigência" (PALLOFF; PRATT, 2015, p. 22). Na pesquisa, um dos pontos positivos do uso do Facebook para fins educacionais levantado pelos participantes, é a possibilidade de proporcionar aos estudantes um espaço de colaboração e interação entre os docentes e discentes, de modo fácil, ágil e democrático, como destacado por P01 e P02:

Atendimento às demandas tecnológicas dos alunos, maior interatividade, participação e colaboração entre alunos e professores e maior agilidade nos processos educativos, bem como na avaliação (P01).

A agilidade e facilidade de acesso e a penetração destas redes nos alunos (P02).

Mesmo que seja considerado um espaço que pode contribuir para a inovação do processo de ensino e aprendizagem e que atenda ao perfil dos estudantes, por se tratar de um espaço social e de lazer, caso seja utilizado de maneira desestruturada e superficial, não proporcionará a motivação necessária para que os estudantes se engajem com as ações educativas propostas. Esse fato fica claramente ilustrado na fala de um participante da pesquisa, quando afirma que:

Caso o que foi proposto na rede social não exija pesquisa e fundamentação, a construção do conhecimento pode ficar superficial. O professor precisa planejar muito precisamente $o$ que será realizado na rede social para que a investigação, a pesquisa e a fundamentação teórica também esteja envolvida no processo. Caso contrário, não atenderá ao teor educacional previsto para este fim (P01). 
A fala de P01 ilustra a afirmação de Moreira e Januário (2014, p. 74) a respeito de que as redes sociais podem facilitar o desenvolvimento de práticas de ensino, contanto que exista uma intencionalidade educativa explícita.

\section{CONSIDERAÇÕES FINAIS}

Com base na análise dos dados, evidencia-se que foi positivo desenvolver a atividade em dois momentos (exposição de fotografias e textos, paralelamente com a disseminação de uma página do Facebook), por propiciar aos apreciadores o entendimento a respeito do tema de modo interativo e dinâmico, os quais puderam participar do processo de construção do próprio conhecimento. Além disso, por meio da mídia on-line, foi possível estender a compreensão e a interação entre um extenso número de pessoas de diversas origens, ultrapassando os muros da instituição.

Constatou-se também que o Facebook pode e deve ser utilizado para finalidades educacionais, pois por meio das funcionalidade e recursos disponíveis, pode contribuir para a criação de práticas de ensino que envolvam o estudante como ator e o professor como parceiro na construção do conhecimento significativo.

Outrossim, percebe-se que cada vez mais os professores estão utilizando o espaço social como ambiente virtual de aprendizagem, por possibilitar aos estudantes um espaço de troca, colaboração e liberdade de expressão, desprendido dos bancos escolares, podendo ser acessado e utilizado em qualquer tempo e lugar.

Para tanto, vale ressaltar que por ser um espaço comumente utilizado para lazer, o docente deve deixar claro os objetivos e planejar as atividades de modo que não se perca a proposta pedagógica.

\section{REFERÊNCIAS}

Amante, L. (2015). Facebook e novas sociabilidades: contributos da investigação. In P. L. Torres (Org.), Redes e mídias sociais (pp.41-62). Curitiba: Appris.

Creswell, J. W. (2010). Projeto de pesquisa: métodos qualitativo, quantitativo e misto. Porto Alegre: SAGE.

Cruz, M. (28 de janeiro de 2016). Facebook revela dados do Brasil na CPBR9 e WhatsApp 'vira ZapZap'. TechTudo. Recuperado de http://www.techtudo.com.br/noticias/noticia/2016/01/facebook-revela-dados-do-brasil-nacpbr9-e-whatsapp-vira-zapzap.html

Ferreira, J. de L., Corrêa, B. R. do P. G. \& Torres, P. L (2012). O uso pedagógico da rede social Facebook. In P. L. Torres \& P. R. Wagner (Orgs.). Redes sociais e educação: desafios contemporâneos. Comunidade Virtual de Aprendizagem. Porto Alegre: EDIPUCRS. Recuperado de http://pead.ucpel.tche.br/revistas/index.php/colabora/article/view/199

Gil, A. C. (2009). Estudo de caso: fundamentação científica, subsídios para coleta e análise de dados, como redigir o relatório. São Paulo: Atlas.

Macedo, N. M. R. \& Ribes, R. (2014). Ser amigo e ter amigos no Facebook: uma análise com crianças. In C. Porto \& E. Santos (Orgs.), Facebook e educação: publicar, curtir, compartilhar (pp.149-166). Campina Grande: EDUEPB. 
Moraes, M. C. (2008). Ecologia dos saberes: complexidade, transdisciplinaridade e educação. São Paulo: Antakarana/WHH - Willis Harman House.

Moreira, J. A. \& Januário, S. (2014). Redes sociais e educação reflexões acerca do Facebook enquanto espaço de aprendizagem. In C. Porto \& E. Santos (Orgs.), Facebook e educação: publicar, curtir, compartilhar (pp.67-84). Campina Grande: EDUEPB.

Okada, A. (2011). colearn 2.0 - Coaprendizagem via comunidades abertas de pesquisa, práticas e recursos educacionais. Revista e-Curriculum, 7(1). Recuperado de http://revistas.pucsp.br/index.php/curriculum/article/viewFile/5813/4128

Palloff, R. M. \& Pratt, K. (2015). Lições da sala de aula virtual: as realidades do ensino on-line. Porto Alegre: Penso.

Prass, R. (10 de maio de 2011). Entenda o que são os 'QR Codes', códigos lidos pelos celulares. G1. Recuperado de http://g1.globo.com/tecnologia/noticia/2011/05/entenda-o-que-sao-osqr-codes-codigos-lidos-pelos-celulares.html

Prensky, M. (2001). Digital Natives, Digital Immigrants. On the Horizon, October 2001, 9 (5). Lincoln: NCB University Press. Recuperado de http://www.marcprensky.com/writing/Prensky\%20\%20Digital\%20Natives,\%20Digital\%20Immigrants\%20-\%20Part1.pdf

Santaella, L. (2014). O leitor ubíquo e suas consequências para a educação. In P. L. Torres (Org.), Complexidade: redes e conexões na produção do conhecimento (pp.27-44). Curitiba: SENARPR.

Sobre nós. (s.d.). Campus Party. Recuperado de http://brasil.campus-party.org/sobre-nos

Sumares, G. (31 de março de 2016). Facebook ainda é a rede social mais usada por jovens, diz pesquisa. Olhar Digital Pro - O futuro passa primeiro aqui. Recuperado de http://olhardigital.uol.com.br/pro/noticia/facebook-ainda-e-a-rede-social-mais-usada-porjovens-diz-pesquisa/56758

Yin, R. K. (2005). Estudo de caso: planejamento e métodos. Porto Alegre: Bookman. 